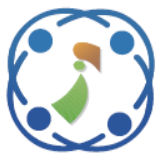

\title{
Design and Fabrication of a Miniature and Compact Tri-band Antenna Using CTSRR Metamaterial and DGS Methods for RFID and WiMAX Applications
}

\author{
Youssef Mouzouna $^{1 *}$ Ahmed Mouhsen $^{1}$ Hanane Nasraoui ${ }^{1} \quad$ Azzeddine Sardi $^{3}$ \\ Mohamed Taouzari ${ }^{2,4}$ Jamal El Aoufi $^{4}$ Mohamed Rafi ${ }^{4}$ \\ ${ }^{1}$ Laboratory IMII, Faculty of Science and technical, FST Settat, Hassan 1st University, Morocco \\ ${ }^{2}$ Laboratory LISA, National School of Applied Sciences, ENSA Berrechid, Hassan 1st University, Morocco \\ ${ }^{3}$ Faculty of Sciences and technical, FST Settat, Hassan 1st University, Morocco \\ ${ }^{4}$ Laboratory of Aeronautical Telecommunication, Mohammed VI, International Academy of Civil Aviation, \\ Morocco \\ *Corresponding Author Email: mouzouna.youssef@ gmail.com
}

\begin{abstract}
This paper presents a new miniaturized microstrip planar tri-band antenna operating at $2.45 \mathrm{GHz}$ and 5.8 $\mathrm{GHz}$ for RFID applications, and $3.5 \mathrm{GHz}$ for WiMAX applications. The proposed antenna is designed by using the slot inserted in its patch, and Complementary Triangular Split Ring Resonator (CTSRR) and Defected Ground Structures (DGS) techniques inserted in its ground plan. The proposed techniques for this antenna is studied, optimised and designed on FR4-epoxy substrate with thickness $\mathrm{h}=1.6 \mathrm{~mm}$, dielectric constant 4.4 , and loss tangent 0.025 , and simulated by using CST microwave studio software. The simulated results offer a good performances in terms of matching and radiation pattern. The proposed antenna is fabricated on the FR-4 epoxy substrate and tested. A good agreement is found between measured and simulated results. The advantages of this antenna are planar, smaller in size, simple structure, three bands, low in cost and easy to be fabricated.
\end{abstract}

Keywords: RFID, WiMAX, Metamaterial, DGS, Reader antenna.

\section{Introduction}

Radio Frequency Identification (RFID) is a technology that uses electronic tags placed on objects, people or animals to relay identifying information to an electronic reader by means of radio $[1,2]$. Nowadays, RFID technology has become widely used in various fields such as transportation payments, asset management, animal identification, retail sales and so on. Traceability and object tracking are one of the most important applications of RFID technology by replacing barcodes with RFID tags or adding barcodes to these tags to achieve many advantages such as ease of reading, long read range and improved data capacity [3]. An RFID system consists essentially of a Tag, which is also composed of antenna for communication, a circuit for storing and processing, RFID reader transmits a radio frequency interrogation signal through the reader antenna and receives the backscattered signal from the antenna of the in-field transponder which contains the stored contents in the internal memory of the tag [4], a host for storage of information collected from tag and treaties. An RFID system can be classified into active RFID system in which an RFID tag has a battery pack and a passive system in which an RFID tag has no battery pack but has the energy to operate the incident wave of reader [5]. RFID systems operate in all frequency ranges but the UHF range (Ultra High Frequency) is the most used due to its high reading distance and a large data transfer rate compared to other HF frequency ranges (High frequency) and LF (Low frequency). WiMAX is one of the recent broadband wireless communication technologies, which supports resources allocation services is extensively used in data, telecommunications (VoIP) and IPTV services (triple play). The bandwidth range 
of WiMAX makes available broadband connectivity through variety of devices to overall the world [6], WiMAX can operate at 2.5, 3.5 and 5.5 GHz. [7]

Since different standards may be used simultaneously in one system, it has become a tendency to design an antenna that can operate at multiple frequency bands [8]. In the literature there are many techniques for miniaturization and adaptation such as, metamaterial (MTMs) [9, 10], High impedance surface (HIS) [11], MagnetoDielectrics [12], reactive impedance surfaces (RIS) [13], fractalization [14], defected ground structures (DGS) $[15,16]$ and so forth. Metamaterials were first introduced by Veselago in 1967 [17], they are artificial Structures which exhibit negative permittivity, permeability and negative refractive index, which is not found in the readily available materials [18, 19]. Metamaterial-based antennas are a class of antennas inspired by metamaterials to enhance their capability or to achieve novel functions [20]. Metamaterial-based small antennas are proposed to provide antennas with a means to manipulate the dispersion relation or the near-field boundary conditions, which could result in antenna size miniaturization while maintaining a good radiation performance [21]. DGS are slots that are compact in geometry and are etched on the ground plane of the microwave circuits (antennas, filters, etc...). DGS comprises of single unit cell (single defect) or a number of a periodic structures. The etching of DGS on the ground plane of an antenna perturbs the current length path, as a result the effective capacitance and inductance changes, thereby resulting in antenna miniaturization [22].

However, defected ground structures (DGS) and metamaterial techniques are still the useful techniques in microstrip multibands antenna design for different applications such as antenna size reduction, compact and effective. Metamaterial techniques are used to get two bands operating. DGS is realized by inserting a shape defected on a ground plane, which has an effect on current distribution depending on its dimensions, and to shift bands for obtaining bands operating. The techniques of DGS and metamaterial are inserted together in this antenna operating in three bands having good advantages in terms of matching, radiation pattern, gain and size.

The rest of this paper is structured as follows: in first part, it is described the design and simulation of the simple rectangular patch antenna using of the equations in order to calculate of the patch's dimensions, then a slot integrated in the patch. Part 2 is devoted to the study and characterization Complementary Triangular Split Ring Resonator (CTSRR). In part 3, the final geometry of the proposed antenna based on the slot, the metamaterial structure and DGS is designed, optimized and simulated in order to operate in three commercials bands (RFID and WiMAX). The part 4 presents the fabrication and the measurement of the proposed antenna. A conclusion is given in the last part.

\section{Studying, design and simulation of the proposed antenna}

Each new design of the planar antenna starts with a rectangular patch shown in Fig. 1 where its dimensions are calculated by the equations mentioned below [21]. Where $W$ and $L$ are the width and the length of the rectangular patch, respectively, $c$ is the free space celerity of light, $\varepsilon r$ is the dielectric constant of the substrate, $\Delta L$ is the length extension and Leff is the effective length, and $f$ is the center frequency.

$$
\begin{aligned}
& W=\frac{c}{2 f \sqrt{\frac{\left(\varepsilon_{r}+1\right)}{2}}} \\
& \varepsilon_{\text {reff }}=\frac{\varepsilon_{r}+1}{2}\left[1+12 \frac{h}{w}\right]^{-\frac{1}{2}} \\
& L=L_{\text {eff }}-2 \Delta L \\
& \Delta L=0.412 h \frac{\left(\varepsilon_{\text {eff }}+0.3\right)\left(\frac{w}{h}+0.264\right)}{\left(\varepsilon_{\text {eff }}-0.258\right)\left(\frac{w}{h}+0.813\right)} \\
& L_{\text {eff }}=\frac{c}{2 f \sqrt{\varepsilon_{\text {eff }}}}
\end{aligned}
$$

The simple rectangular patch antenna with simple ground is designed and simulated on microstrip FR-4 substrate with a relative permittivity of $\varepsilon_{r}=4.4$ and tangent loss of 0.025 and thickness of $1.6 \mathrm{~mm}$. The Fig. 1 shows its layout using 3D CST microwave studio simulator. The curve named antenna 1 shown in Fig. 3 presents the reflection coefficient result. In order to improve the results. The first technique proposed is to insert a slot in the patch as shown in Fig. 2, the curve named antenna 2 presents the reflection coefficient, 


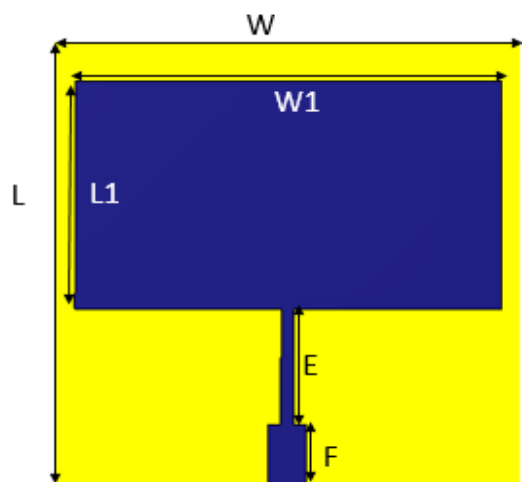

(a)

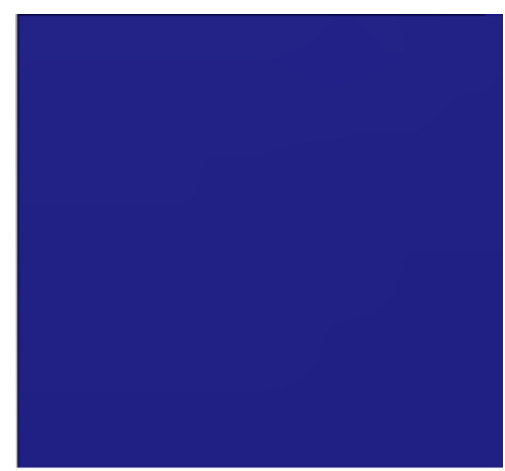

(b)

Figure. 1 Design of the antenna 1: (a) patch and (b) ground plan

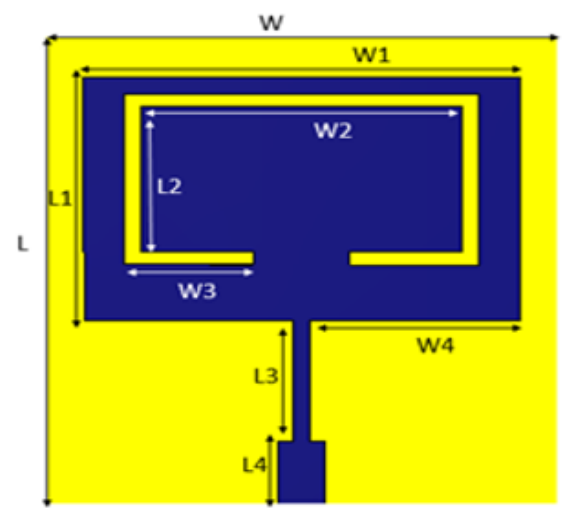

(a)

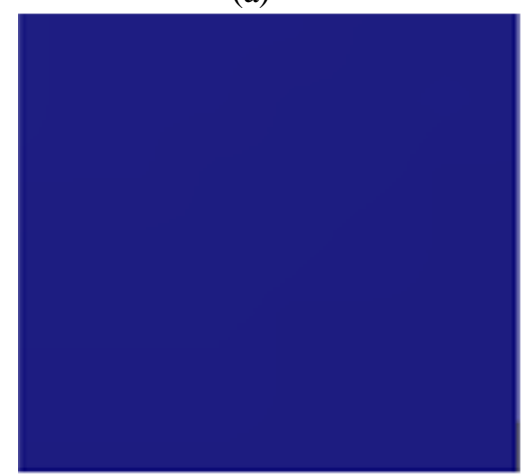

(b)

Figure. 2 Design of the antenna 2: (a) patch and (b) ground plan
Table 1. Parameter of the antenna1

\begin{tabular}{|c|c|c|c|}
\hline Parameter & $\begin{array}{c}\text { Value } \\
(\mathbf{m m})\end{array}$ & Parameter & $\begin{array}{c}\text { Value } \\
(\mathbf{m m})\end{array}$ \\
\hline L & 34 & $\mathrm{~W}$ & 32 \\
\hline L1 & 18.5 & $\mathrm{~W} 1$ & 27 \\
\hline E & 9.25 & $\mathrm{~F}$ & 5 \\
\hline
\end{tabular}

Table 2. Parameter of the antenna2

\begin{tabular}{|c|c|c|c|}
\hline Parameter & $\begin{array}{c}\text { Value } \\
(\mathbf{m m})\end{array}$ & Parameter & $\begin{array}{c}\text { Value } \\
(\mathbf{m m})\end{array}$ \\
\hline L & 34 & $\mathrm{~W}$ & 32 \\
\hline L1 & 18.5 & $\mathrm{~W} 1$ & 27 \\
\hline L2 & 11 & $\mathrm{~W} 2$ & 20 \\
\hline L3 & 9.25 & $\mathrm{~W} 3$ & 7 \\
\hline L4 & 5 & $\mathrm{~W} 4$ & 13 \\
\hline
\end{tabular}

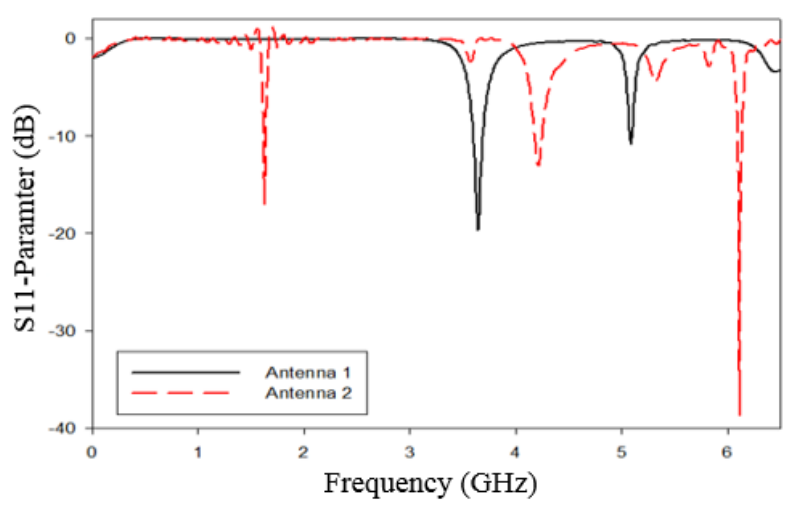

Figure. 3 The simulated coefficient of reflexion of the tow antennas

The results of the antenna with slot (antenna 2 curve) give three bands (1.7 GHz, $4.2 \mathrm{GHz}$ and 6.2 $\mathrm{GHz}$ ) which are not bands desired proposed above. In order to improve and design a miniaturized antenna with good performances in terms of a matching, pattern radiation and band width, and three bands commercials of RFID and WiMAX applications, the two others techniques called metamaterial [22] and defected ground structure (DGS) will be integrated in ground plan of the antenna with slot. In this part, firstly, the metamaterial resonator proposed in this work called Complementary Triangular Split Ring (CTSR) is study, optimized and simulated for the three dimensions (Radius (R), Width (W) and Gap (G)). The Fig. 4 presents of the configuration of the Complementary Triangular Split Ring Resonator. While the Figs. 5, 6, and 7 illustrate the results of transmission coefficient $(\mathrm{S} 21)$ at the resonance frequency $5.8 \mathrm{GHz}$ of the three dimensions optimized. For the radius optimization, as can been seen from Fig. 5 that the optimal value at the resonance frequency $(5.8 \mathrm{GHz})$ is $7 \mathrm{~mm}$, while the optimal values of the width and gap optimization (Figs. 6 and 7) are $0.5 \mathrm{~mm}$ and $0.75 \mathrm{~mm}$, respectively. 


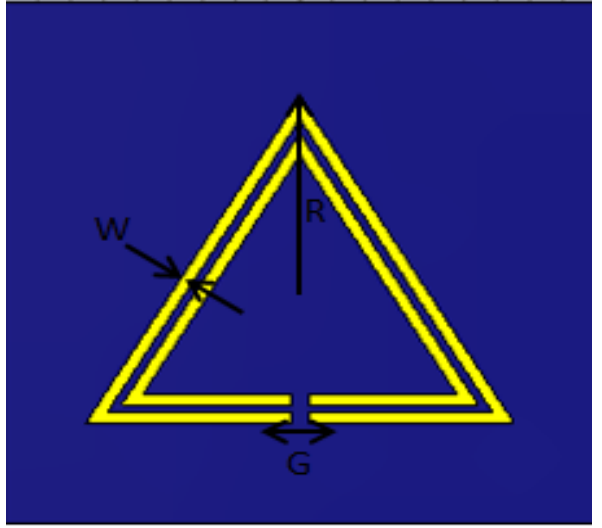

Figure. 4 Design of the Complementary Triangular Split Ring Resonator (CTSRR)

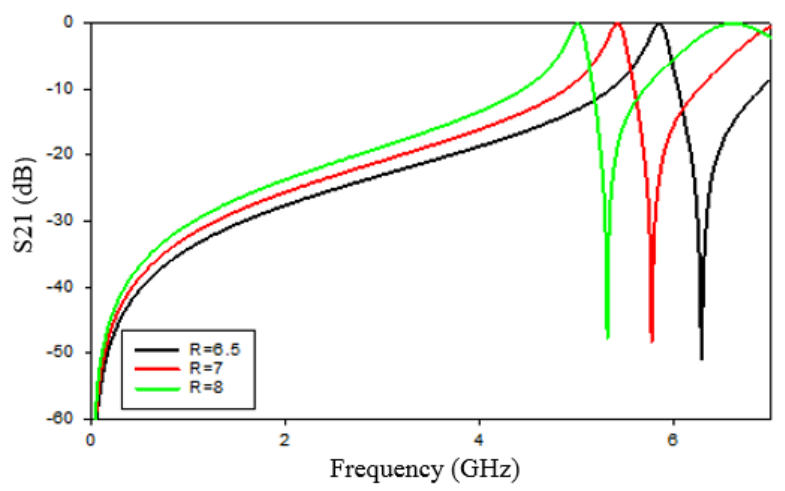

Figure. 5 Simulated results of the radius optimization of the complementary triangular split ring resonator

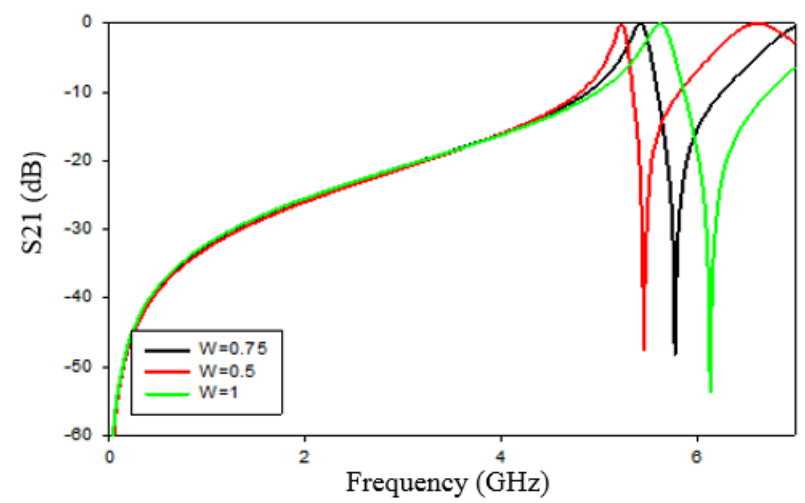

Figure. 6 Simulated results of the width optimization of the complementary triangular split ring resonator

In this part of work, our objective is to analysis the performances of the proposed antenna with respect to the increment of CTSRR unit cell. Thus, the dual CTSRR illustrated in Fgure. 8 is designed, optimized and simulated. From the simulation results shown in Figs. 9 and 10, Both the permittivity and permeability are found to be negative at the resonance frequencies of the operating bands $(2.45 \mathrm{GHz}, 3.5$ $\mathrm{GHz}, 5.8 \mathrm{GHz}$ ). All simulations show that the dual CTSRR proposed is well designed and it can be integrated in the antenna structure.

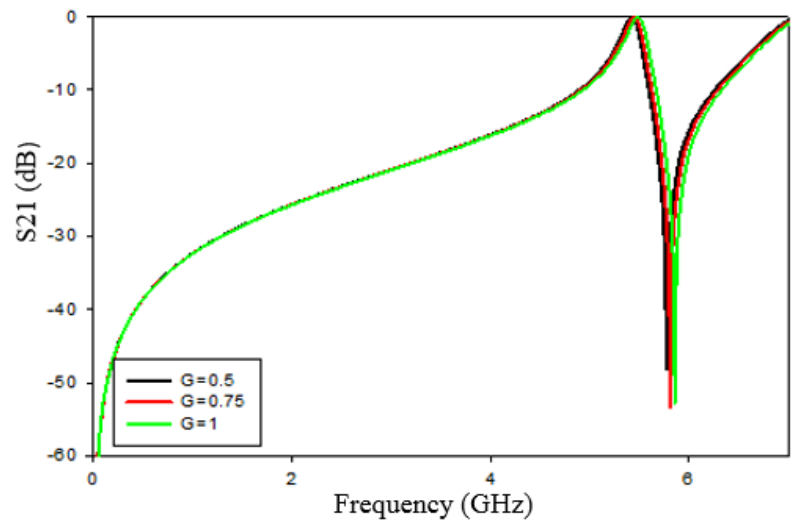

Figure. 7 Simulated results of the gap optimization of the complementary triangular split ring resonator

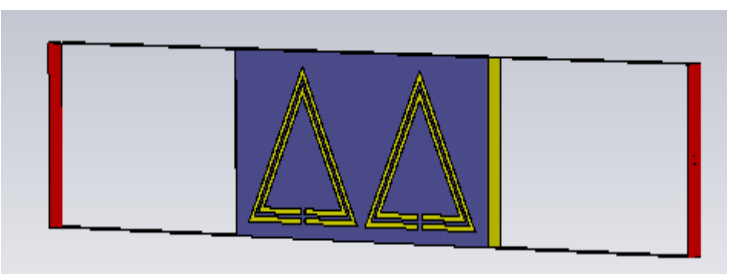

Figure. 8 Design of the dual CTSRR using CST 3D simulator

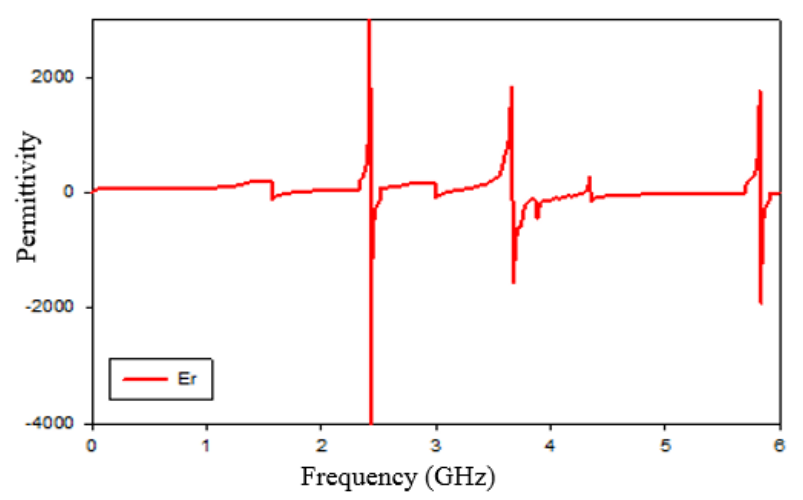

Figure. 9 Simulated results of the permittivity at the resonance frequencies of the operation bands

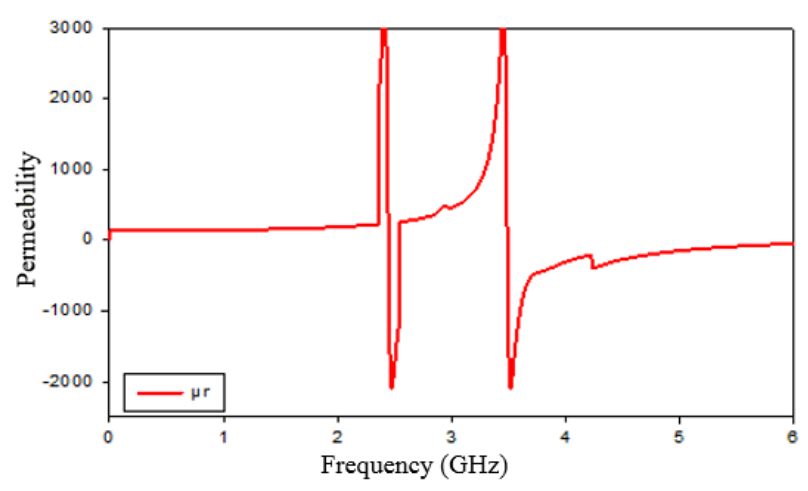

Figure. 10 Simulated results of the permeability at the resonance frequencies of the operation bands

The dual CTSRR is integrated in the ground plan of the antenna with slot in its patch as shown in Fig.11. The result simulation of the reflection coefficient of 
this antenna is depicted in Fig. 12; it's well observed that a good matching is obtained at $2.45 \mathrm{GHz}$ with $16 \mathrm{~dB}, 3.75 \mathrm{GHz}$ with $-15,9 \mathrm{~dB}$ and at $5.18 \mathrm{GHz}$ with $12.4 \mathrm{~dB}$. As mentioned above, that the proposed antenna must operate at the three bands $(2.45 \mathrm{GHz}$, $3.5 \mathrm{GHz}$, and $5.8 \mathrm{GHz}$ ), it is can be seen that a little shift of the resonance frequency is found for the two bands $(3.5 \mathrm{GHz}$ and $5.8 \mathrm{GHz})$. To have an antenna works exactly at the commercial three bands, the third method is proposed, it is called Defected Ground Plan. Many of the DGS types presented in Fig. 13 are designed, optimized and simulated in order to get a good matching at the resonances frequencies of the operating bands. After this figure, a Good matching is obtained and presented in yellow curve.

The final design of the proposed antenna using the slot, CTSRR and DGS techniques is presented in Fig. 14, and its detailed dimensions are enlisted in Table 3. The results simulation of the reflection coefficient, radiation pattern and gain are depicted from Fig. 15 to Fig. 19.

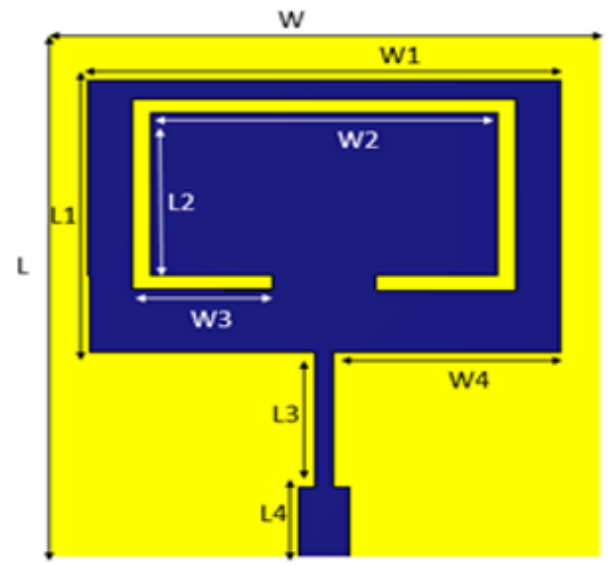

(a)

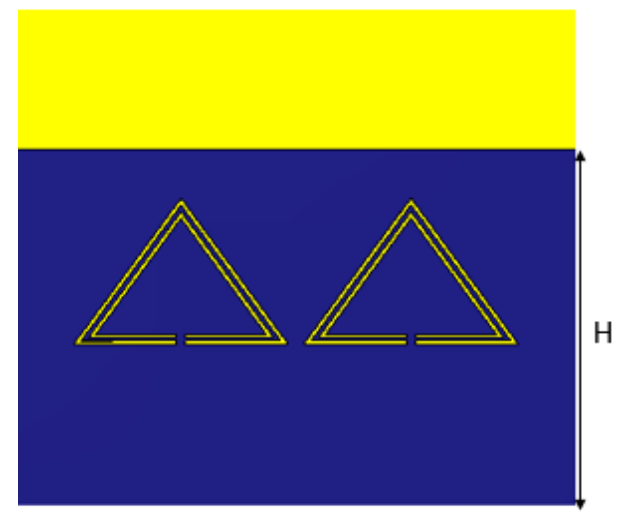

(b)

Figure. 11 The antenna structure with the metamaterial structure: (a) top antenna and (b) ground plan

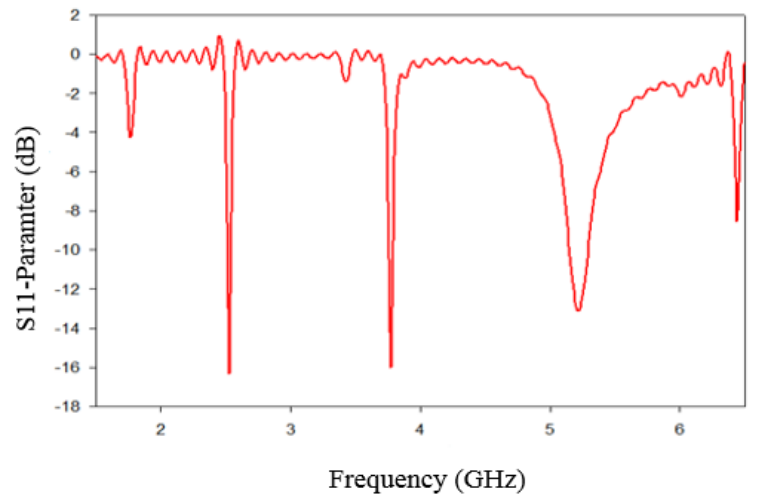

Figure. 12 The reflection coefficient of the antenna with metamaterial structures

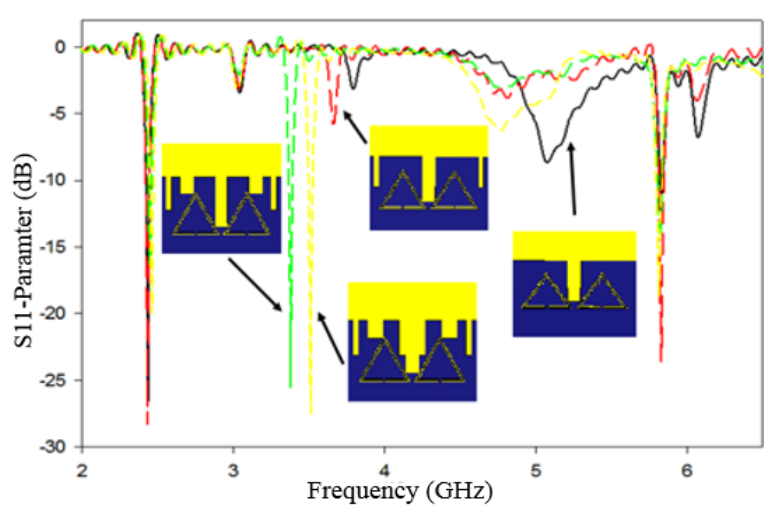

Figure. 13 Different slot inserted and their effect on the performance of the antenna

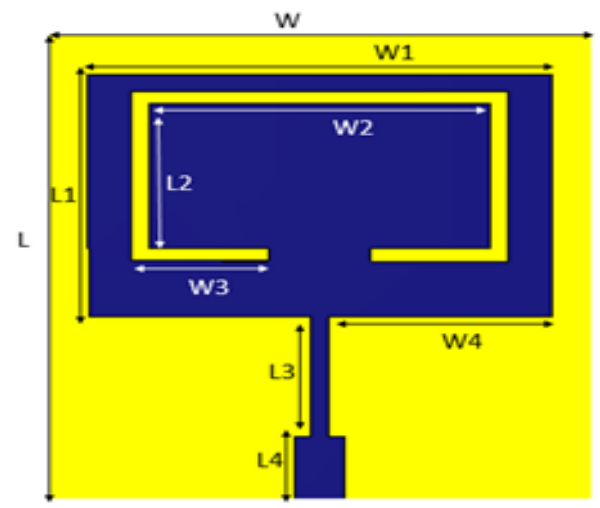

(a)

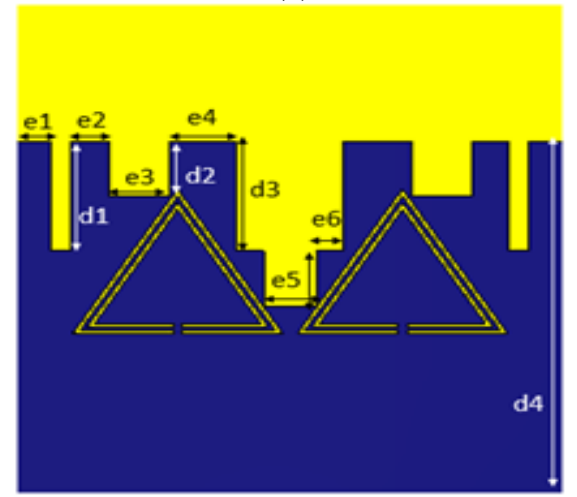

(b)

Figure. 14 The final design of the proposed antenna using 3D CST: (a) patch and (b) ground plan 
Table 3. Parameter of the antenna

\begin{tabular}{|c|c|c|c|}
\hline Parameter & $\begin{array}{c}\text { Value } \\
(\mathbf{m m})\end{array}$ & Parameter & $\begin{array}{c}\text { Value } \\
(\mathbf{m m})\end{array}$ \\
\hline $\mathrm{L}$ & 34 & $\mathrm{~d} 2$ & 4 \\
\hline $\mathrm{L} 1$ & 18.5 & $\mathrm{~d} 3$ & 8 \\
\hline $\mathrm{L} 2$ & 11 & $\mathrm{~d} 4$ & 25.27 \\
\hline $\mathrm{L} 3$ & 9.25 & $\mathrm{e}$ & 1 \\
\hline $\mathrm{L} 4$ & 5 & $\mathrm{e} 1$ & 2.15 \\
\hline $\mathrm{W}$ & 32 & $\mathrm{e} 2$ & 2.15 \\
\hline $\mathrm{W} 1$ & 27 & $\mathrm{e} 3$ & 3.5 \\
\hline $\mathrm{W} 2$ & 20 & $\mathrm{e} 4$ & 3.9 \\
\hline $\mathrm{W} 3$ & 7 & $\mathrm{e} 5$ & 3 \\
\hline $\mathrm{W} 4$ & 13 & $\mathrm{e} 6$ & 1.6 \\
\hline $\mathrm{d} 1$ & 8 & & \\
\hline
\end{tabular}

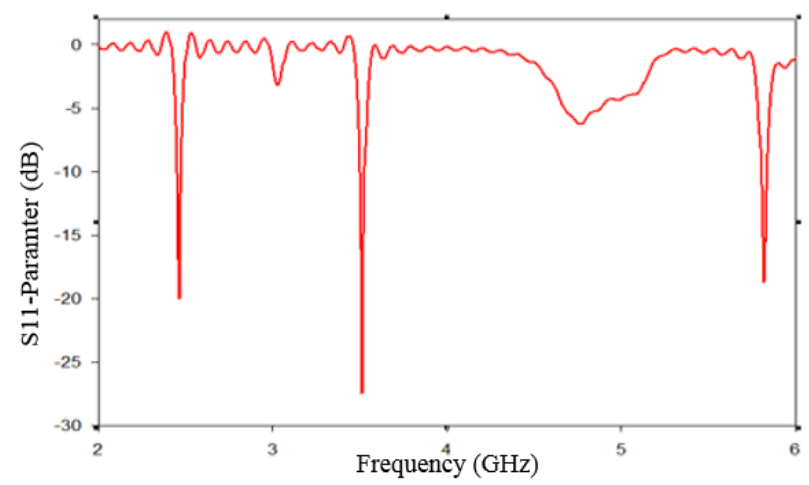

Figure. 15 The reflection coefficient of the final structure of the antenna

For the reflection coefficient results illustrated in Fig. 15, a good matching is obtained at $2.45 \mathrm{GHz}$ with $-20 \mathrm{~dB}$, at $3.5 \mathrm{GHz}$ with $-27 \mathrm{~dB}$, and at $5.8 \mathrm{GHz}$ with $-18 \mathrm{~dB}$. The proposed antenna with good matching for the three operating bands (RFID and WiMAX) is achieved.

For the 2D radiation diagram of the E-plan and $\mathrm{H}$ plan results of the three resonances frequencies $(2.45$ $\mathrm{GHz}, 3.5 \mathrm{GHz}$ and $5.8 \mathrm{GHz}$ ) depicted in Fig. 16, Figs. 17 and 18, respectively. As we can see for the both plans that, the radiation pattern is a bidirectional. it represents an opening angle of 87.7 degrees for $2.45 \mathrm{GHz}, 75$ degrees for $3.5 \mathrm{GHz}$ and 84 degrees for $5.8 \mathrm{GHz}$.

For the gain results shown in Fig. 19, it is well observed that the gain is over $1 \mathrm{dBi}$ at the resonance frequency of each operating band, where $3.5 \mathrm{dBi}$ at $2.45 \mathrm{GHz}, 3.1 \mathrm{dBi}$ at $3.5 \mathrm{GHz}$ and 4.4 at $5.8 \mathrm{GHz}$.

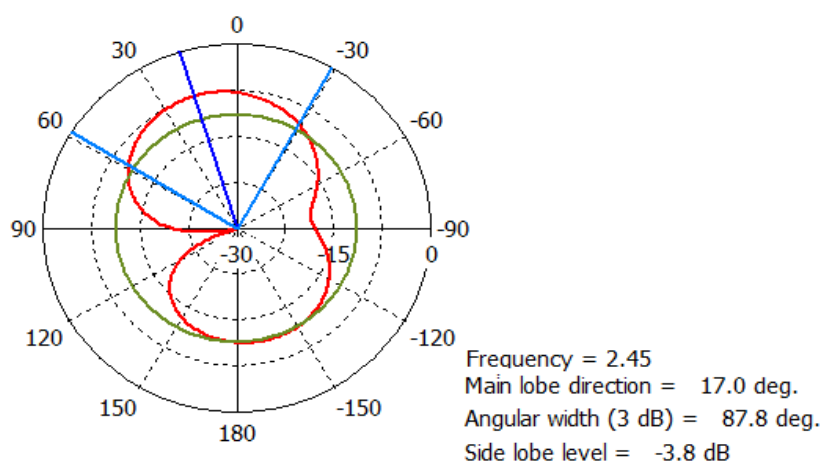

(a)

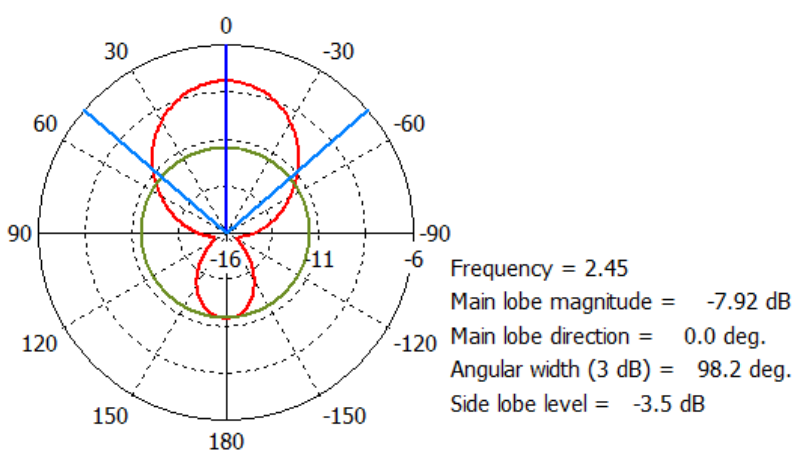

(b)

Figure. 16 The simulated Radiation pattern of the antenna at 2.45GHz: (a) H-plane and (b) E-plane

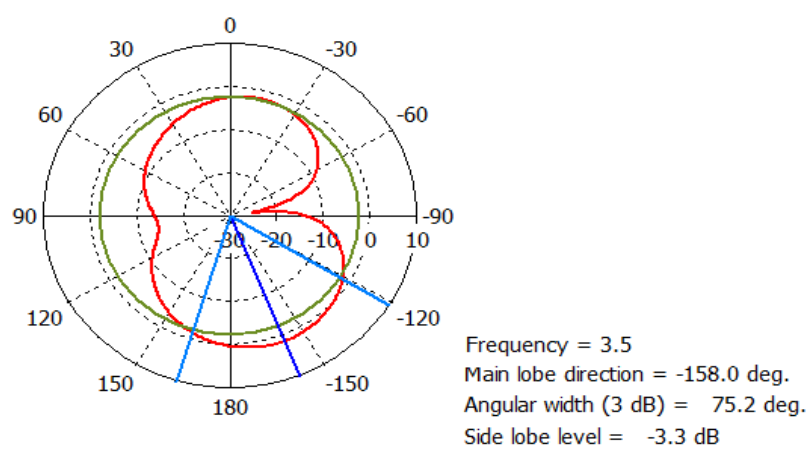

(a)

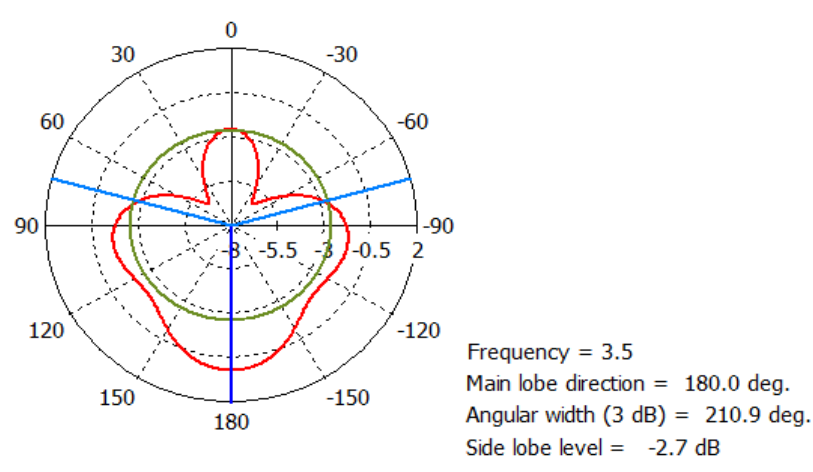

(b)

Figure. 17 The simulated Radiation pattern of the antenna at 3.5GHz: (a) H-plane and (b) E-plane 


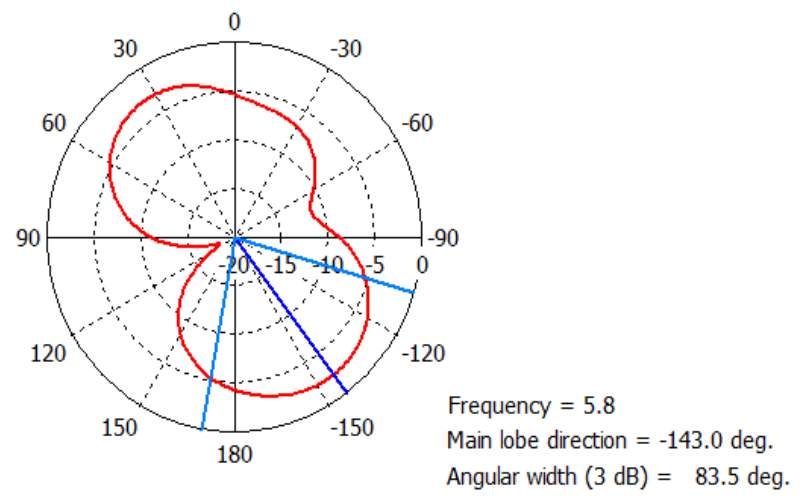

(a)

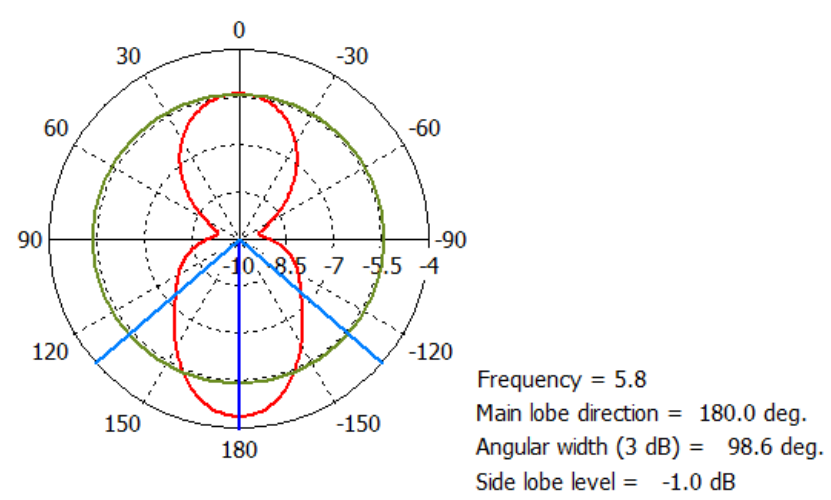

(b)

Figure. 18 The simulated Radiation pattern of the antenna at 5.8 GHz: (a) H-plane and (b) E-plane

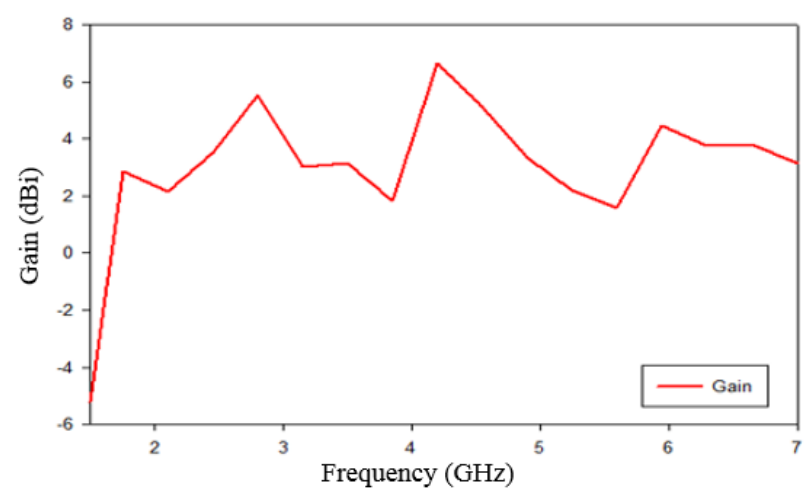

Figure. 19 The Gain of the antenna versus frequency

\section{Fabrication and measurement results}

A prototype of the proposed antenna as shown in Fig. 20 was fabricated and tested to validate the simulated results. The antenna is manufactured by using LPKF machine and is printed on FR-4 substrate with a permittivity of 4.4 and a thickness of $1.6 \mathrm{~mm}$.. The whole size of the proposed antenna is $34 \times 32$ $\mathrm{mm}^{2}$, and patch total size is around $13.5 \times 27 \mathrm{~mm}^{2}$. An Agilent vector network analyser was used to take the reflection coefficient.).

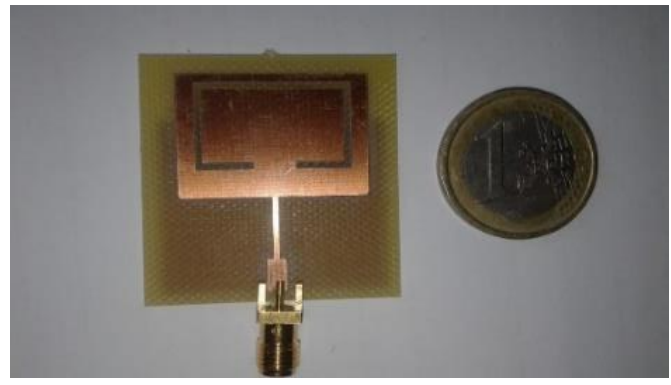

(a)

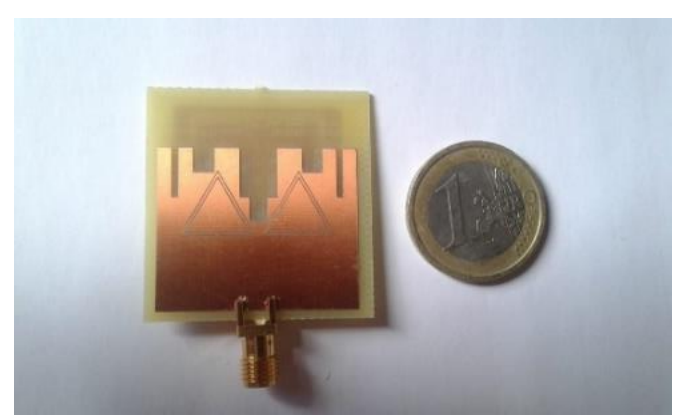

(b)

Figure. 20 Photograph of the fabricated antenna: (a) top view and (b) bottom view

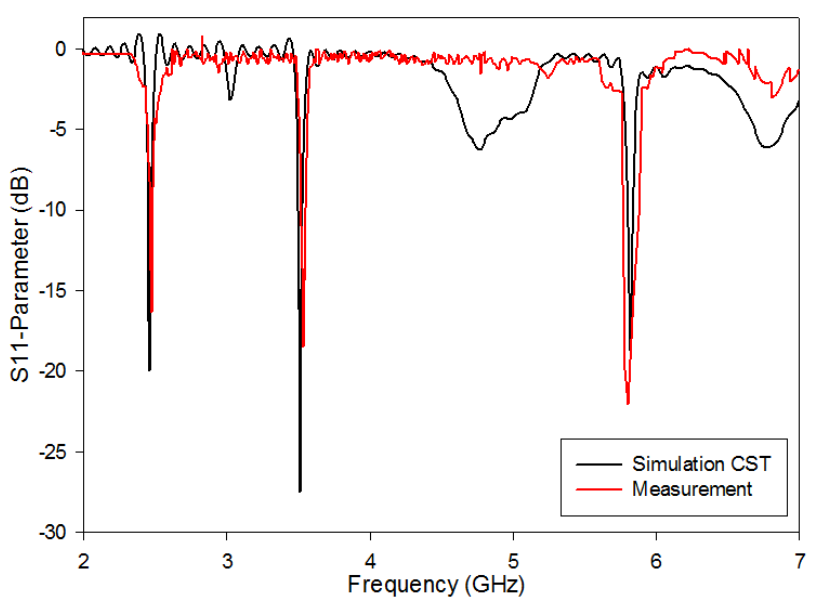

Figure. 21 Measured and simulated results of the reflection coefficient

The measured and simulated return loss versus frequency is presented in Fig. 21, which shows the comparatively good agreement. It is observed from Fig. 21 that the measured reflection coefficient is less than $-15 \mathrm{~dB}$ at $2.45 \mathrm{GHz},-18 \mathrm{~dB}$ at $3.5 \mathrm{GHz}$ and -20 $\mathrm{dB}$ at $5.8 \mathrm{GHz}$. The slight frequency shift between the measured and simulated results can be mostly attributed to the fabrication tolerance.

The proposed is mounted and tested in order to measure a gain as shown in Fig. 22. Fig. 23 presents the variation of the gain versus frequency. As can been seen that a good value of the measured gain is obtained for the three operations bands with $2.9 \mathrm{dBi}$ at $2.45 \mathrm{GHz}, 3.25 \mathrm{dBi}$ at $3.5 \mathrm{GHz}$ and 4.35 at $5.8 \mathrm{GHz}$. 

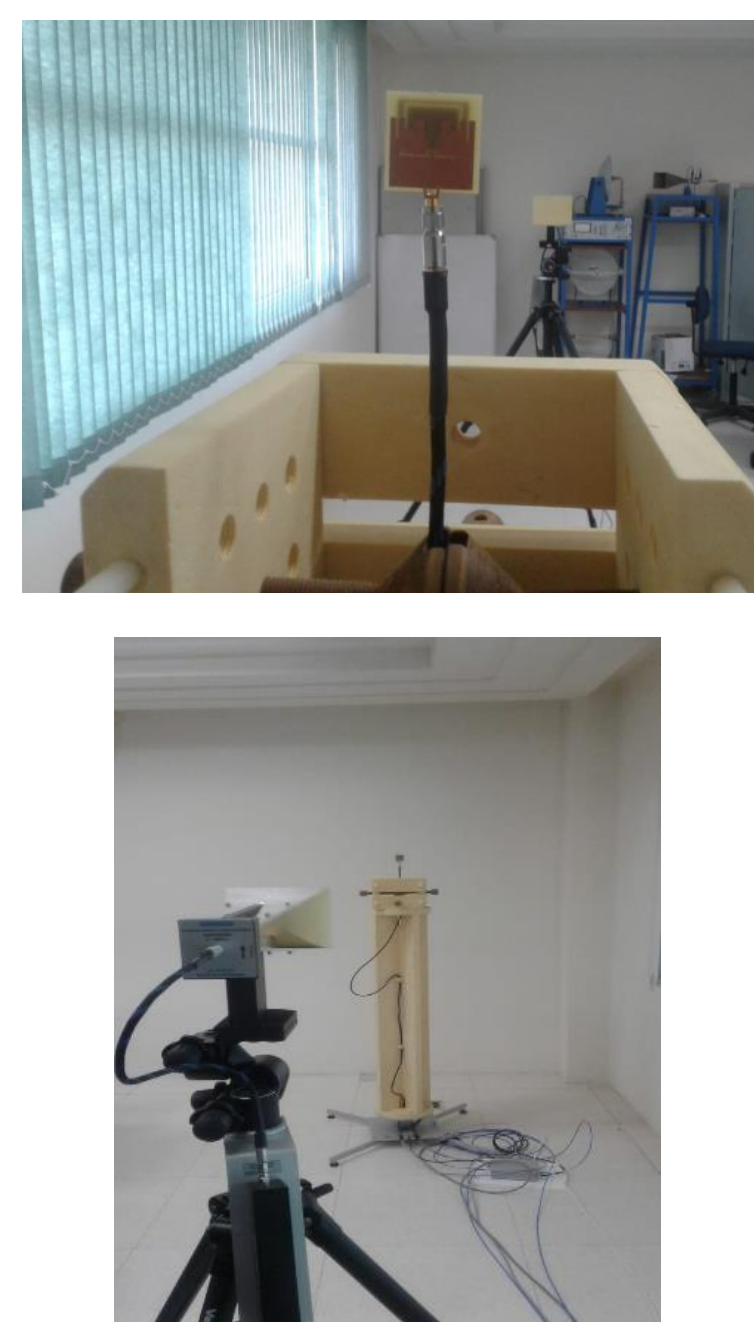

Figure. 22 Photograph of the proposed antenna during the measure of the gain

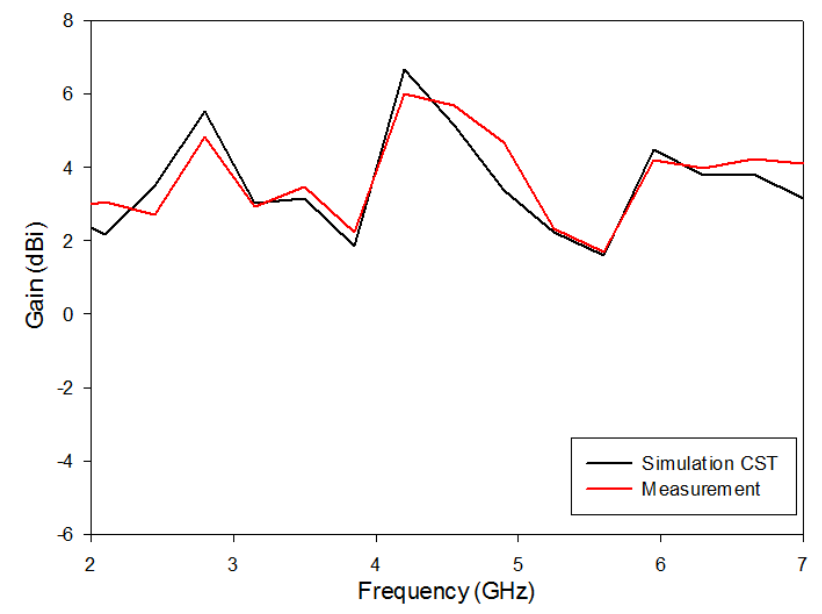

Figure. 23 Measured and simulated results of the gain versus frequency

The proposed antenna in this work presents good performances in terms of matching, radiation pattern, gain, number of the bandwidth, and size in compared with the works recently published as enlisted in Table 3.
Table 3. The proposed work compared to other works already published.

\begin{tabular}{|c|c|c|c|c|c|c|}
\hline \multicolumn{2}{|c|}{$\begin{array}{c}\text { Reference } \\
\text { number }\end{array}$} & {$[7]$} & {$[23]$} & {$[24]$} & {$[25]$} & $\begin{array}{c}\text { This } \\
\text { work }\end{array}$ \\
\hline $\begin{array}{c}\text { Dimension } \\
\left(\mathbf{m m}^{2}\right)\end{array}$ & 300 & 6912 & 1296 & 2310 & 1088 \\
\hline $\begin{array}{c}\text { Resonant } \\
\text { frequenc } \\
\mathbf{y} \\
\text { (GHz) }\end{array}$ & F1 & 2.5 & 2.45 & 2.45 & 0.9 & 2.45 \\
\cline { 2 - 7 } & F2 & 3.5 & 4.5 & ----- & 2.45 & 3.5 \\
\cline { 2 - 7 } & F3 & 5.8 & 5.8 & 5.8 & 5.8 & 5.8 \\
\hline \multirow{2}{*}{$\begin{array}{c}\text { Gain } \\
(\mathbf{d B})\end{array}$} & F2 & 1.47 & ---- & ---- & 5.3 & 3.25 \\
\cline { 2 - 7 } & F3 & 2.9 & ---- & 3 & 7 & 4.35 \\
\hline
\end{tabular}

\section{Conclusion}

A Novel three bands microstrip antenna based on slots method, Complementary Triangular Split Ring Resonator (CTSRR) metamaterial and Defected Ground Plan (DGS) techniques is analyzed, designed and fabricated. The measured results obtained show that this antenna offers a good matching, good radiation pattern and gain for three bands with center frequencies at 2.4/3.5/5.8 GHz. Due to a simple and miniature structure, this antenna can fulfil the requirement of RFID/WiMAX applications such simple integration. As future work, new methods will be based on metamaterial and DGS techniques in order to get tri bands antenna with improvement in bandwidth.

\section{References}

[1] Frigui, M.S. Kraoui, H. Ghariani, and M. Lahyani, "New Folded Tag Antenna with Chanel Shaped Matematriel", International Journal on Communications Antenna and Propagation, Vol.6, No.6, 2016.

[2] K. Finkinzeller, "RFID for the Supply Chain and Operations Professional, Second Edition", paperback, 2016.

[3] M. Youssef, M. Taouzari, H. Nasraoui, A. Sardi, A. Mouhsen, and J. Elaoufi, "Designing of a New Miniaturized Tag Antenna Using the Meander Technique and Low Cost Paper Substrate for Bottle Labeling Applications", 
International Journal on Communication Antenna and Propagation, Vol.8, No.3, 2018.

[4] A. Elhamraoui, E. Abdelmounim, J. Zbitou, H. Bennis, and M. Latrach, "A New Design of a Microstrip Antenna with Modified Ground for RFID Applications", International Journal of Intelligent Engineering and Systems, Vol.11, No.6, pp.44-51, 2018.

[5] Y. Mouzouna, H. Nasraoui, A. Mouhsen, and J. El Aoufi, "Miniaturized meander antenna using low cost paper substrate", In: Proc. of the 5th International Conference on Multimedia Computing and Systems, 2016.

[6] G. Meyyappan, M. Govindan, and E. Chikkannan, "Dynamic Power Efficient Resource Allocation for 802.16 WiMAX Network", International Journal of Intelligent Engineering and Systems, Vol.10, No.4, pp.265273, 2017.

[7] A. Kunwar, A.K. Gautam, and K. Rambabu, "Design of a Compact U-Shaped Slot Triple Band Antenna for WLAN/WiMAX Applications", International Journal of Electronics and Communication, Vol.71, pp.8288, 2017.

[8] H. Li, Y. Zhou, and X. Mou, Z. Ji, "Miniature Four-band CPW-Fed Antenna for RFID/WiMAX/LAN Applications", IEEE Antennas and Wireless Propagation Letters, Vol.13, pp.1684-1688, 2014.

[9] T. Ali and B. C. Rajashekhar, "A compact multiband antenna using $\lambda / 4$ rectangular tangular stub loaded with metamaterial for IEEE 802.11N and IEEE 802.16E", Microwave and Optical Technology Letters, Vol. 59, No.5, pp.1000-1006, 2017.

[10] R.O. Ouedraogo, E. J. Rothwell, A. R. Diaz, K. Fuchi, and A.Temme, "Miniaturization of patch antennas using a metamaterial-inspired technique", IEEE Transaction Antennas Propagation, Vol. 60, No. 5, pp.2175-2182, 2012.

[11] J. McVAY, N. Engheta, and A. Hoorfar, "Highimpedance metamaterial surfaces using Hilbertcurve inclusions", IEEE Microwave and Wireless Components Letters, Vol. 14, No. 3, pp.130-132, 2004.

[12] P. M. T. Ikonen, K. N. Rozanov, A. V. Osipov, P. Alitalo, and S. A Tetaykov, "Magnetodielectric substrates in antenna miniaturization: Potential and limitations", IEEE Transaction on Antennas and Propagation, Vol. 54, No. 11, pp. 3391-3399, 2006.

[13] H. Mosallaei and K. Sarabandi, "Antenna miniaturization and bandwidth enhancement using a reactive impedance substrate", IEEE Transaction on Antennas and Propagation, Vol.52, No.9, pp.2403-2414, 2007.

[14] J. Anguera, C. Puente, C. Borja, and J. Soler, "Fractal shaped antennas: A review", Encyclopedia of $R F$ and Microwave Engineering Wiley, 2005.

[15] A. Salih and M. Sharawi, "A dual-band highly miniaturized patch antenna", IEEE Antennas Wireless Propagation Letters, Vol.15, pp.17831786, 2016.

[16] M. Taouzari, J. El Aoufi, A. Mouhsen, H. Nasraoui, and O. El Mrabat, "900 MHz and 2.45 $\mathrm{GHz}$ Compact Dual-Band Circularly Polarized Patch Antenna for RFID Application", In: Proc. of the Conference on Microwave Techniques, 2015.

[17] V. G. Veselago, "The electrodynamics of substances with simultaneously negative values of $\mu$ and $\varepsilon "$, Soviet Physics Uspekhi, Vol.10, No.4, pp.509-514, 1968

[18] E. Bahar and N. J. Ianno, "Complex media characterized by chirality and negative refractive index: analysis and applications", Journal of Nanophoton, Vol.1, No.1, 2007.

[19] B. Nasiri, A. Errkik, J. Zbitou, A. Tajmouati, L. El Abdellaoui, and M. Latarch, "A Miniature Microstrip BSF Using Complementary Split Ring Resonator", International Journal of Intelligent Engineering and Systems, Vol.11, No.3, pp.29-36, 2018.

[20] Y. Dong and T. Itoh, "Metamaterial-Based Antennas", IEEE Proceeding, Vol.100, No.7, pp. 2271 - 2285, 2012.

[21] C. A. Balanis, "Antenna Theory and design, second edition", John Wiley \& Sons, 1997.

[22] H. Nasraoui, A. Capobianco, A. Mouhsen, J. El Aoufi, Y. Mouzouan, and M. Taouzari, "Compact wideband band pass microstrip filter loaded by triangular split ring resonator", Microwave and Optical Technology Letters, Vol.59, No.12, pp.3101-3107, 2017

[23] M. A. M. El-Negm Yousef and A. B. AbdelRahman, "Realization OF Multi-band Antenna for WiMAX and RFID by Etching Two Interlaced Triangles from Delta Resonator", In: Proc. of National Radio Science Conference, pp.79-86, 2017.

[24] A. Ennajih, J. Zbitou, M. Latrach, A. Errkik, L. El Abdellaoui, and A. Tajmouati, "Dual Band Metamaterial Printed antenna based on CSRR for RFID application", International Journal of Microwave and Optical Technology, Vol.12, No.2, pp.106-113, 2017. 
[25] [25] B. Wang and W. Wang, "A niniature triband RFID reader Antenna with high gain for portable device", International Journal of Microwave and Wireless Technologies, Vol.9, No.5, pp.1163-1167, 2016. 